\title{
O DESIGN POR NÃO-DESIGNERS DAS RUAS DE BELO HORIZONTE
}

\author{
Ibarra, María Cristina.; MSc; \\ Universidade do Estado de Minas Gerais \\ mariacih@gmail.com \\ Ribeiro A.C., Rita.; Dra; \\ Universidade do Estado de Minas Gerais \\ rribeiroed@gmail.com
}

Resumo: Este trabalho apresenta o perfil dos artefatos resultantes do Design por não-designers (DND) encontrados em Belo Horizonte. Este termo foi adotado em nossa pesquisa para fazer referência ao desenvolvimento de soluções materiais que não têm relação com a academia, ou seja, artefatos que são produzidos e pensados por pessoas que não possuem conhecimentos formais na área do design. Através da descrição das suas caraterísticas principais, estipuladas a partir da análise do discurso de outros autores, e das fotografias tiradas em seus lugares de uso, criamos uma categorização tomando em conta cinco aspectos que consideramos principais, exemplificamos com casos encontrados na cidade e, finalmente, analisamos a importância que tem para o design o estudo deste tipo de prática e suas manifestações. Desta maneira, pretendemos contribuir com a documentação dos artefatos do DND na cidade, que retratam os modos de viver e ver o mundo das pessoas que continuamente têm contato com rua, e das quais o design pode aprender lições.

Palavras chaves: Artefatos populares, Cultural matéria, Design por não designers.

Abstract This work presents the profile of the resulting artifacts of the Design by Non-designers (DND) founds in Belo Horizonte. This term was adapted in our research to refer to the development of material solutions that do not have relation with academy, in other words, artifacts that are produced and thought by people who do not have formal knowledge of design. Through the description of its principal characteristics, stipulated based on the discourse of others authors and on the photographs taken in its places of use, we created a categorization, taking into account five aspects that we considered as the most important ones, we exemplified with the cases found in the city and, finally, we analyzed the importance of this kind of activity and its manifestations for design. Thus, we intended to contribute with the documentation of the artifacts of the DND in the city, that portray the ways of living and seeing the world of people that 
continuously have contact with the streets, and from which design can learn lessons.

Keywords: Popular artifacts. Material culture. Design by non-designers.

\section{INTRODUÇÃO}

O Design por não-designers (DND) foi o termo que adotamos em nossa pesquisa para fazer referência ao desenvolvimento de soluções materiais que não têm relação com a academia, ou seja, $\operatorname{artefatos}^{1}$ que são produzidos e pensados por pessoas que não possuem conhecimentos formais na área do design.

Vários pesquisadores da área têm se referido a este tema como "Design vernacular", "Design espontâneo", "Design pelos outros 90\%", "Desenho vernacular", "Design alternativo", "Non-professional design", "Low Cost design", "Design da Periferia", "Non Intencional Design”, "Adhocismo", "Intuitive Design” (FINÍZOLA, 2010; PELLEGRINI FILHO, 2009; MARTINS 2005; CARDOSO, 2003; SANTOS, 2003; BORGES, 2011; BOUFLEUR, 2006; PEREIRA, 2004; DONES, 2004; VALESE, 2007, FUKUSHIMA, 2009, PERRA, 2010, PACEY, 1992, BRANDES E ERLHOFF, 2006, JENCKS E SILVER 1972; FULTON, 2005) e o têm abordado principalmente a partir de 5 pontos de vista diferentes: Como estes objetos representam culturalmente um lugar específico, como a carência e a falta de recursos incentivam a criatividade e a invenção, como estes objetos podem contribuir para a sustentabilidade, como os novos usos que os usuários dão aos artefatos industriais se transformam em design, e como estes objetos podem contribuir para design chamado 'acadêmico'.

Com o seguinte artigo pretendemos apresentar o perfil dos artefatos resultantes do DND encontrados nas ruas de Belo Horizonte, através da descrição das suas caraterísticas principais estipuladas a partir da análise do discurso de outros autores e das fotografias tiradas em seus lugares de uso. Desta maneira, pretendemos contribuir com a documentação dos artefatos do DND em Belo Horizonte, que retratam os modos de viver e ver o mundo das pessoas que continuamente têm contato com rua, e das quais o design pode aprender lições.

\section{PERFIL DOS ARTEFATOS ENCONTRADOS}

O perfil dos artefatos resultantes do DND encontrados em Belo Horizonte foi gerado começando como uma revisão bibliográfica de trabalhos feitos por autores nacionais e estrangeiros com o propósito de conhecer a abordagem de cada um. $O$ segundo passo foi fazer um mapeamento destes artefatos principalmente na área central de Belo Horizonte, dividida por nós em 3 zonas: (1) Zona do Mercado Central, (2) Zona hospitalar e (3) Zona da Savassi (FIG.1). Como cenário principal, escolhemos maiormente feiras feitas na rua como a Feira das Flores e a Feira Hippie, espaços

${ }^{1} \mathrm{O}$ termo o artefato é empregado com a seguinte acepção: "Forma individual de cultura material ou produto deliberado da mão-de-obra humana" HOUAISS, A. Dicionário Houaiss da Língua Portuguesa. Rio de Janeiro. Ed. Objetiva. 2001 
públicos com grande afluência de pessoas como a Praça Sete de Setembro, Praça Hugo Werneck, Praça da Savassi, Praça da Liberdade, Praça Rio Branco, os arredores do Mercado Central, do Edifício Maletta e de alguns centros médicos da Zona Hospitalar, assim como ruas principais da cidade como: a Rua da Bahia, Av. Augusto de Lima, Rua Curitiba, Av. Afonso Pena, Av. Francisco Sales, Av. João Pinheiro, Av. Brasil, Av. Prof. Alfredo Balena, Av. Paraná, etc. Nossa escolha do centro de Belo Horizonte deve-se a esta área caracterizar-se por ter uma grande atividade comercial durante o dia e à noite, somado à variedade de feiras que acontecem durante a semana e ao grande fluxo de pessoas que percorrem suas ruas.

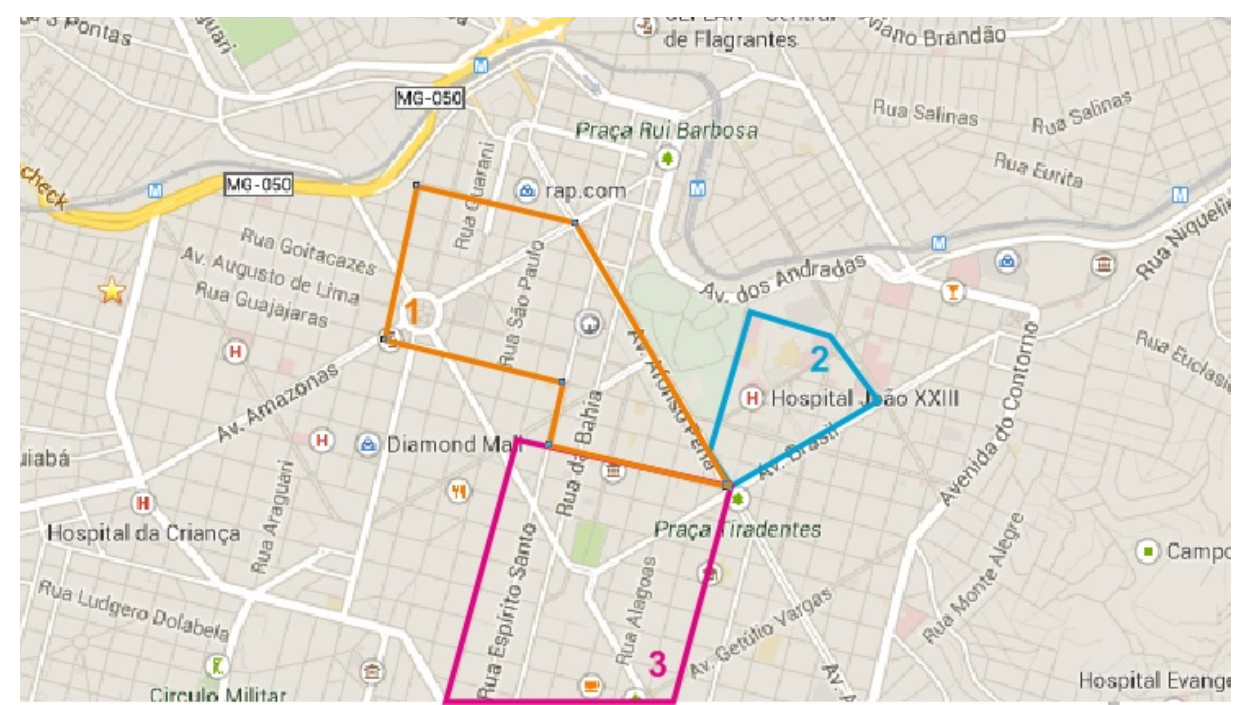

Figura 1 - Zonas de mapeamento. Fonte: Mapa tomado do Google Maps com modificações da autora

Após o mapeamento e do seu registro, fez-se uma seleção das melhores fotografias e os casos mais significativos (foram selecionados mais de 80 artefatos), e foram escolhidos 5 aspectos para facilitar a descrição e a leitura das caraterísticas dos artefatos encontrados: Materiais, autor, possibilidade de deslocamento, modos de produção e uso. (FIG. 2) A continuação falaremos de cada um deles.

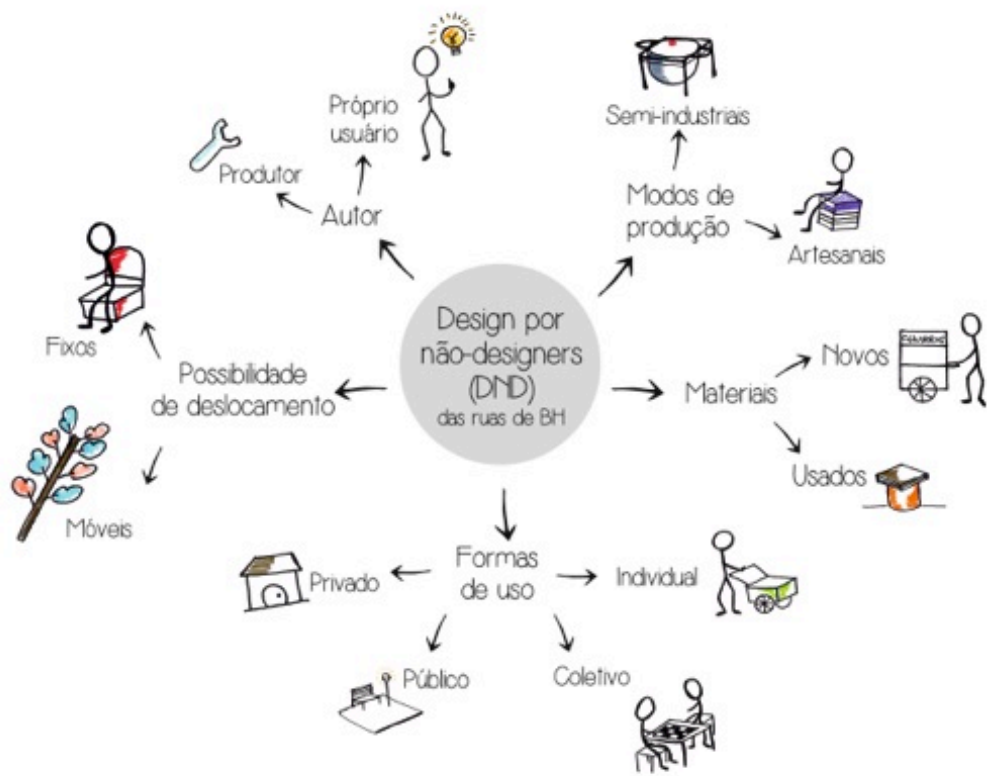

Figura 2 - Perfil dos Artefatos encontrados. Fonte: Criado pela autora com dados extraídos de outros autores 
Com relação aos materiais, de acordo com outros autores, muitos dos artefatos encontrados nas ruas feitos por pessoas que não têm conhecimentos formais em design são uma suma de elementos usados. Este fenômeno é citado por Boufleur (2006) como pós-uso e por Fukushima (2009), pesquisador do tema em Curitiba (PR), como a transformação ou reconfiguração de outros artefatos industriais preexistentes. Nas ruas de Belo Horizonte encontramos artefatos que cumprem este enunciado, como é, entre outros, o caso deste banco feito a partir de um tubo de PVC e papelão (FIG. 3-A). Mas, também encontramos artefatos feitos com materiais novos, como por exemplo, o material usado nos carrinhos para vender churros, que pode ser chapa branca galvanizada pré-pintada ou aço inox (FIG. 3-B).

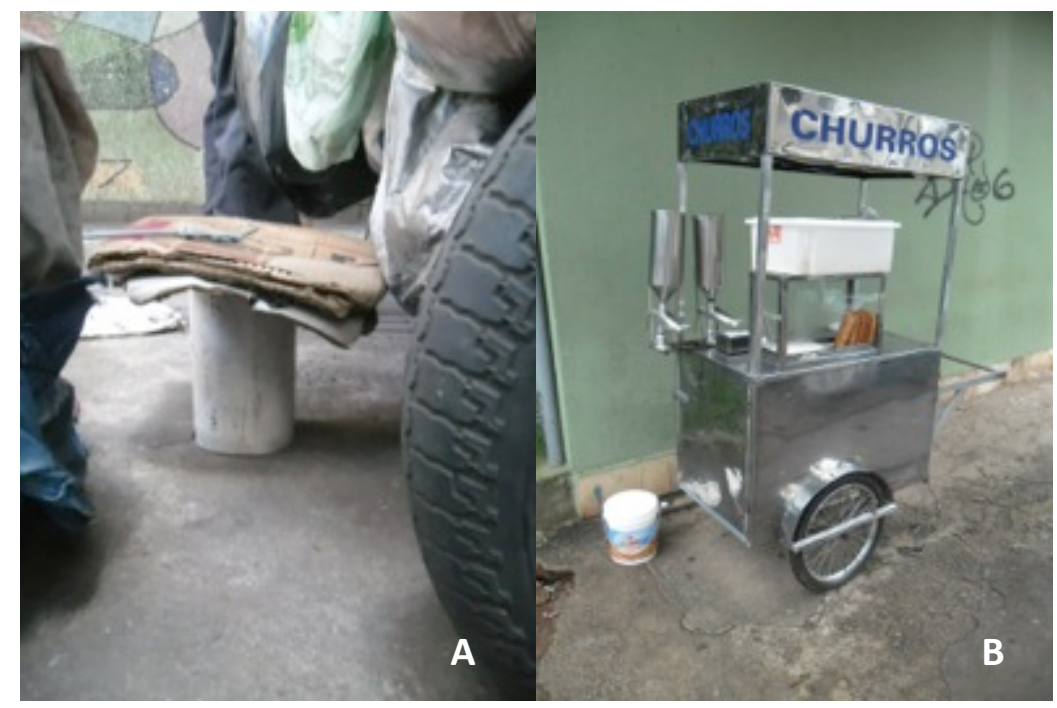

Figura 3 - A. Banco feito com um tubo de PVC e papelão na rua Espirito Santo. B. Carrinho para vender Churros na Av. Brasil. Fonte: Fotos da Autora

Com referência ao autor, os artefatos do DND podem ser feitos por um produtor ou pelo próprio usuário. Em Belo Horizonte, encontramos os dois casos. Latas para vender amendoim nas ruas feitas pelo próprio vendedor ou por uma terceira pessoa. O primeiro caso é do Senhor Daniel (FIG.4-A), que faz suas próprias latas há muitos anos, e o segundo é da Senhora Eva que recebe as latas feitas por um sobrinho, mas é ela quem torra o produto, faz os cartuchos e o embala. (FIG. 4-B)

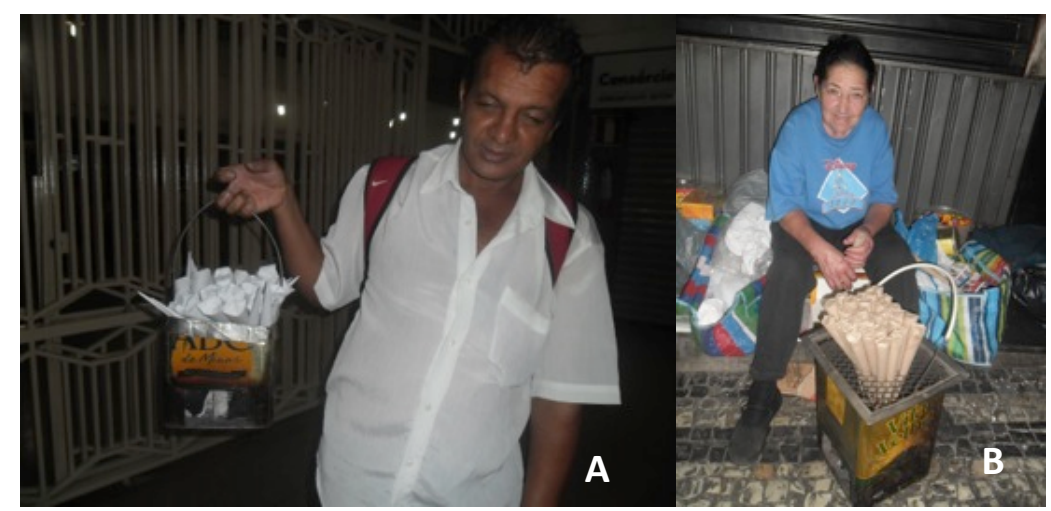

Figura 4 - Vendedores de Amendoim no Edifício Maletta. Fonte: Fotos da Autora

No tocante ao deslocamento dos artefatos do DND, segundo Valese (2007), pesquisadora do tema em São Paulo, existem artefatos fixos e móveis. Os artefatos 
fixos "são aqueles cuja função não requer o movimento constante do artefato para a venda dos produtos". Como por exemplo, barracas expositoras, bandejas fixas e expositores no chão (VALESE, 2007, pág. 24) E os artefatos móveis são aqueles "confeccionados para uso em movimento, com o objetivo de oferecer serviços e produtos aos clientes/consumidores", como por exemplo: as carroças dos catadores, o carrinho de café, de amolar facas, a lata para vender amendoim, etc. (VALESE, 2007, pág. 30). Encontramos em Belo Horizonte, como exemplo dos artefatos fixos, esta poltrona usadas pelos engraxates localizados na Praça Sete de Setembro (FIG.5-A), ponto fixo há muitos anos e que facilita a fidelidade dos seus clientes.

Por outro lado, como artefatos móveis, podemos citar como exemplo o vendedor de algodão doce (FIG. 5-B) que utiliza uma piteira feita a partir de um tronco de pita (Furcraea foetida), (LAMAS; MARQUEZ; CANÇADO; 2011) onde coloca o produto para ser vendido pelas ruas.

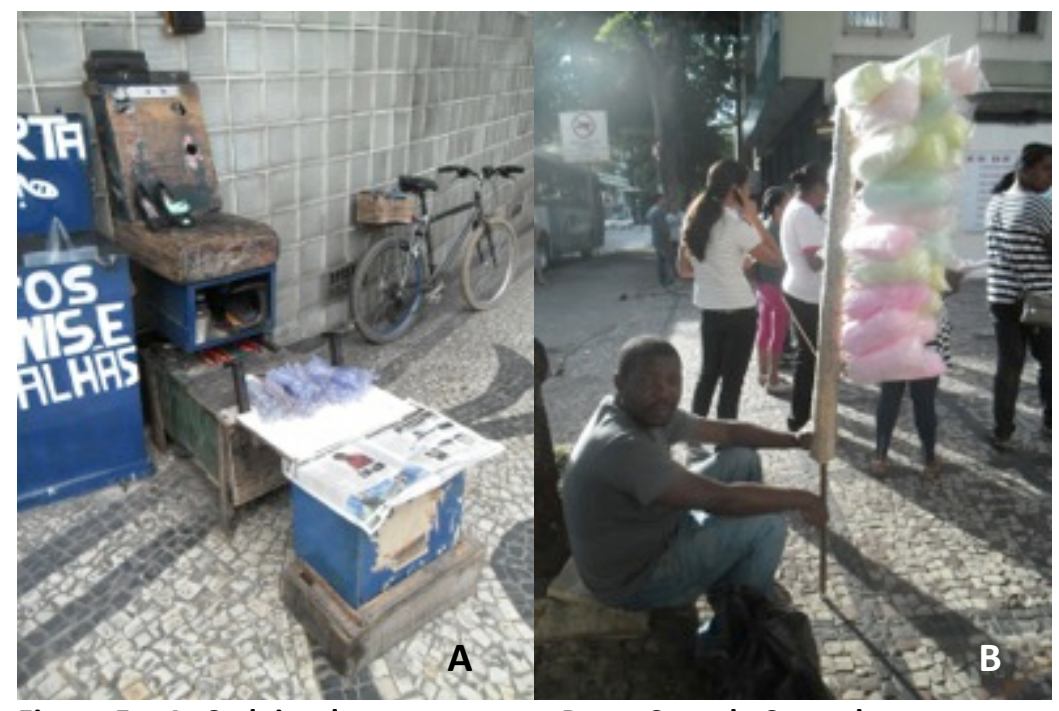

Figura 5 - A. Cadeira de engraxate na Praça Sete de Setembro

B. Vendedor de Algodão Doce na Av. Cristóvão Colombo. Fonte: Fotos da Autora

Também existem vários artefatos que oferecem as duas possibilidades: podem se deslocar ou podem ficar fixos num lugar. É o caso deste carrinho (FIG. 6) feito com ferro, solda e metalão, que permite o deslocamento para encontrar mais clientes, mas cujo dono, o senhor Tarciso, por sua deficiência visual, permanece certas jornadas em um lugar só. Dentro de nossa pesquisa descobrimos que esse vendedor ambulante tem vários pontos fixos na cidade: Rua da Bahia, Av. Afonso Pena, Av. Amazonas, Rua São Paulo, Rua Carijós e Rua Tupinambás. 


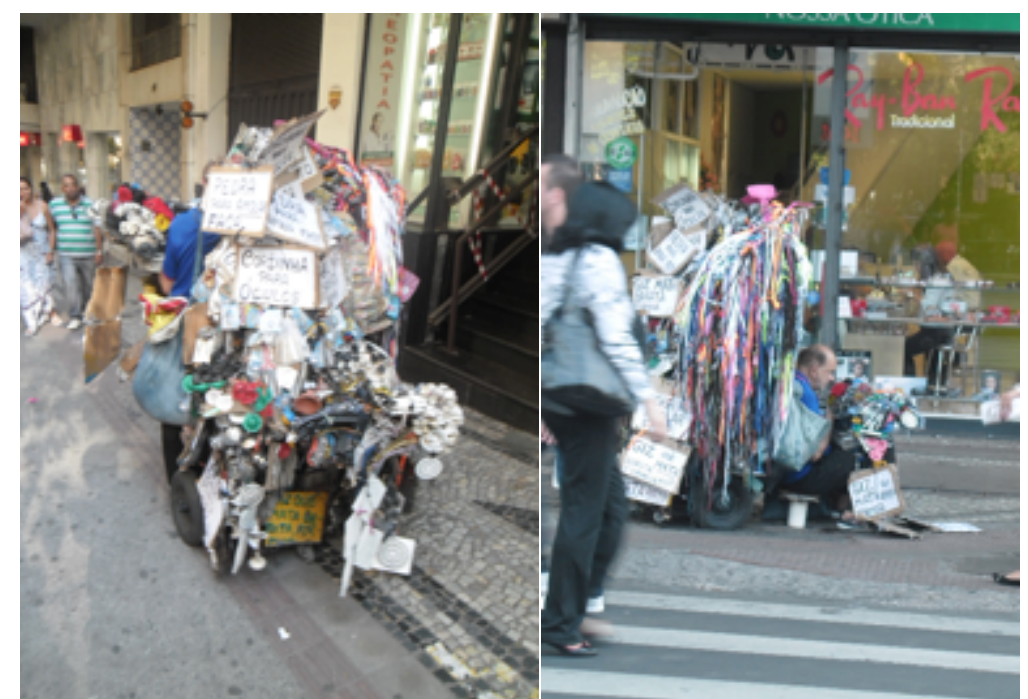

Figura 6- Vendedor Ambulante nas ruas Rua Goitacazes e Bahia. Fonte: Fotos da Autora

Com relação à forma de produção, esse tipo de artefato, segundo Valese (2007) é feito principalmente com as mãos (produção artesanal), ou com a ajuda de instrumentos e máquinas que facilitam sua realização (produção semi-industrial) e permitem a manipulação e a transformação dos materiais. A autora denota que os artefatos semi-industriais são criados a partir de um ferramental apropriado e adequado aos materiais com técnicas de solda e rebite, por exemplo. (VALESE, 2007). Nas ruas de Belo Horizonte encontramos artefatos feitos principalmente com as mãos, como por exemplo, o banquinho feito por um consertador de guarda-chuvas (FIG. 7) a partir de elementos próximos como um caixote para transportar bananas e o tecido impermeável da parte superior de um guarda-chuva amarrado com fios nas extremidades para se ajustar ao tamanho do caixote. Também encontramos artefatos produzidos com materiais e processos semi-industriais que exigem ferramentas que são de uso comum na fábrica, como exemplo, este fogão portátil feito a partir de perfis de ferro e solda. (FIG. 8)

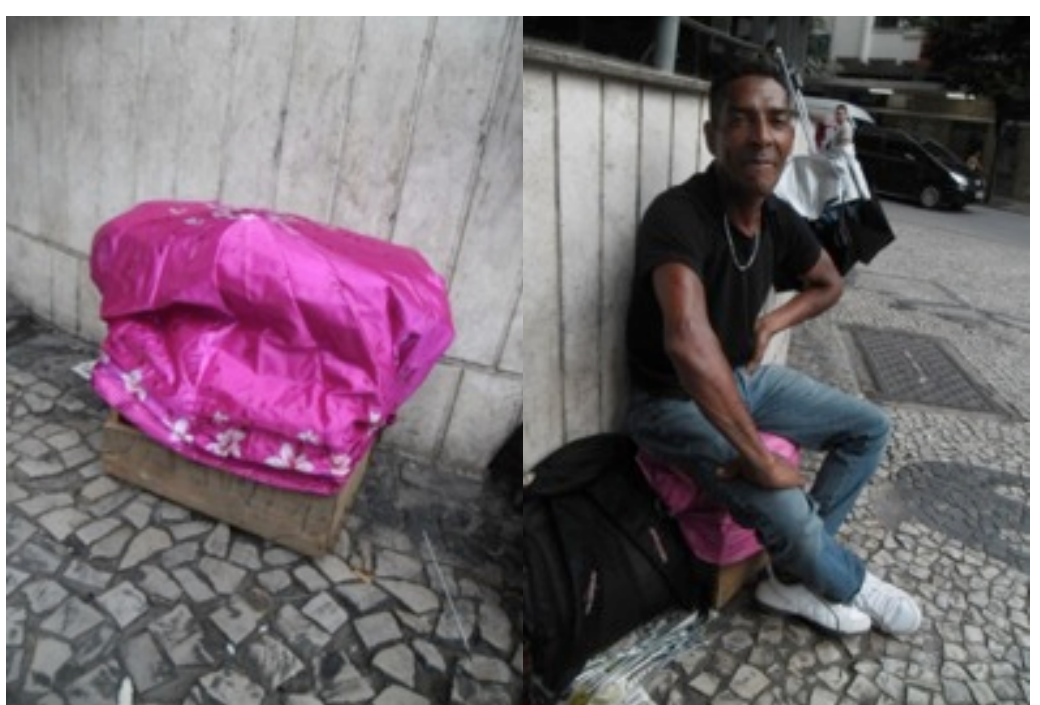

Figura 7 - Banquinho feito a partir um caixote na Av. Amazonas. Fonte: Fotos da Autora 


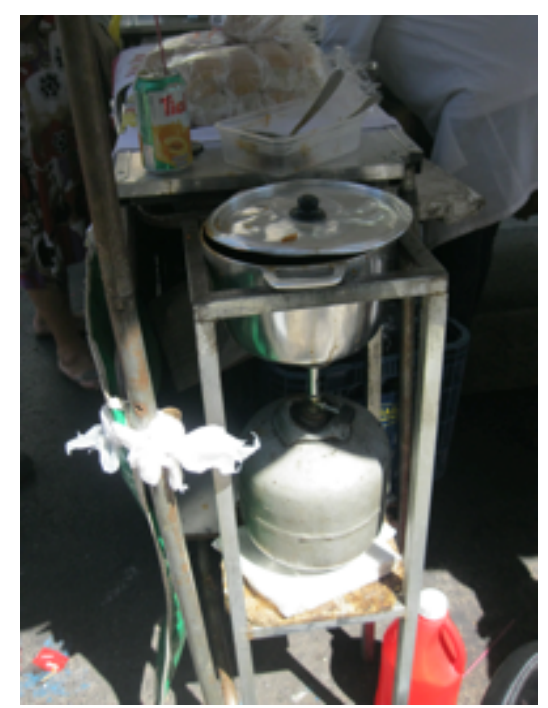

Figura 8 - Fogão portátil na Feira Hippie da Av. Afonso Pena. Fonte: Foto da autora

Por último, com relação ao uso, podemos dizer que encontramos artefatos que são de uso público, privado, individual e coletivo. De uso público, ou seja, que está disponível para todas as pessoas, sem distinção, podemos colocar como exemplo este cinzeiro feito a partir de um recipiente de plástico e cimento encontrado em uma praça da cidade. (FIG. 9)

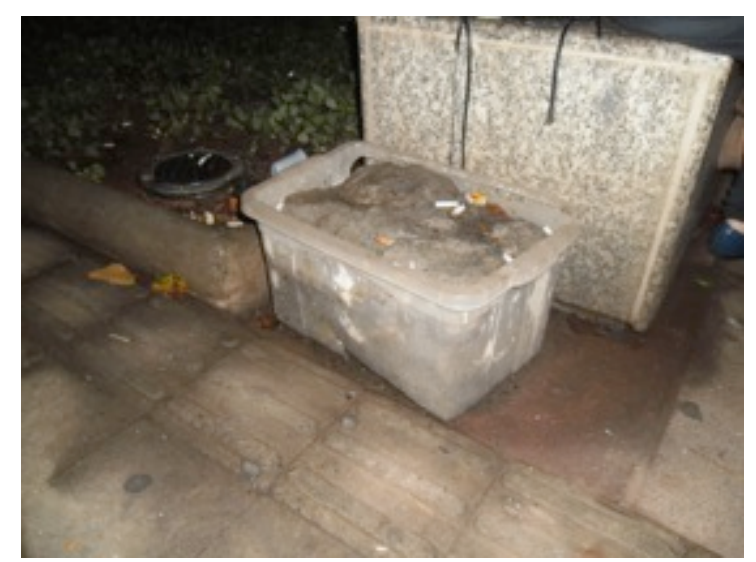

Figura 9- Cinzeiro na Praça da Savassi. Fonte: Foto da autora

De uso privado, é possível citar muitos exemplos. A maioria dos artefatos encontrados não estão disponíveis para serem usados livremente por outras pessoas. É o caso dos artefatos feitos por moradores de rua ou por vendedores ambulantes.

Com relação aos artefatos que são usados por muitas pessoas, ou que tem um uso coletivo, encontramos objetos como lixeiras, caixas de papelão que viraram tapetes em época de chuva, cinzeiros, carros de venda de cachorro quente, mesas para jogar damas, etc. (FIG. 10-A). Porém, a maioria é de uso individual, como os carrinhos dos catadores, dos vendedores de sorvetes, bebidas, plantas, brincos, etc., banquinhos, baldes, rampas, etc. (FIG. 10-B) 


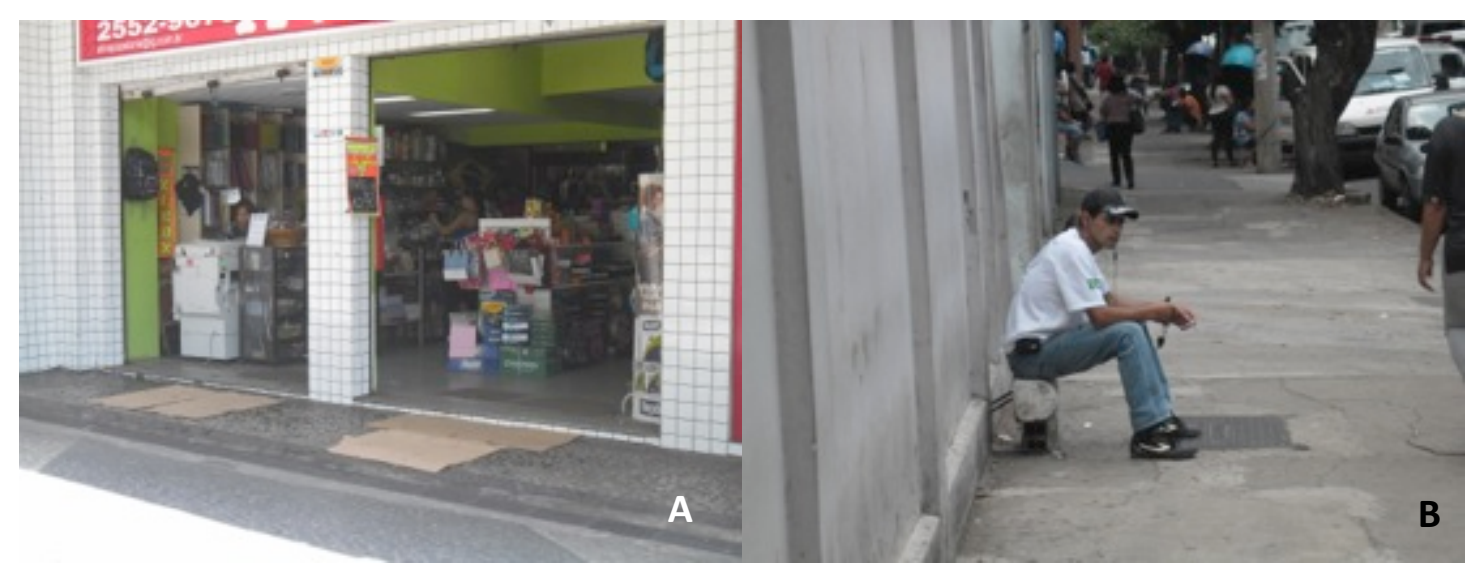

Figura 10 - A. Tapete feito a partir de uma caixa de papelão na Av. Augusto de Lima B. Banquinho na rua na Rua Piauí. Fonte: Fotos da autora

\section{CONCLUSÃO}

Podemos dizer que os artefatos resultantes do DND nas áreas pesquisadas em Belo Horizonte são feitos a partir de materiais novos e usados, alguns são feitos pelo próprio usuário, e outros são feitos por um terceiro, seja com intenção de lucro ou não. Encontramos alguns com possibilidade de deslocamento, ou seja, móveis, e outros que não proporcionam essa possibilidade, ou seja, fixos. E em relação ao uso, foram achados artefatos para serem utilizados individualmente, coletivamente, de forma privada e de forma pública.

São vários os fatores que falam da importância do estudo desse tipo de prática e suas manifestações para o design Em primeiro lugar, segundo Aloísio Magalhães (1977), em países como o Brasil é fundamental que o design abra seus horizontes e deixe de produzir apenas bens de consumo. Igualmente, para Uta Brandes, professora da Koeln International School of Design na Alemanha, e pesquisadora do tema, é necessário que o design se expanda em direção a outras áreas de maneira que possa atuar de uma forma interdisciplinar que the proveja impulsos para a análise da cultura do dia-a-dia (BRANDES; STICH; WENDER; 2009). Ou seja, o estudo destas manifestações faz com que o design adquira uma visão mais holística permitindo-lhe atuar em outras áreas relacionadas com o cotidiano das cidades e abrangendo áreas mais teóricas que vão além da geração de produtos.

Por outro lado, o estudo deste tipo de manifestações nos permite ver uma faceta da cultura material do território pesquisado, neste caso, Belo Horizonte. O DND, seja feito com materiais novos ou através do reuso, é uma prática que reflete a maneira local de resolver problemas, suprir necessidades e dos modos de coisificar ideias e sentimentos de uma comunidade, e exemplifica o repertório objetal que pode se encontrar nesse contexto. Eles são a expressão legítima de um modo de viver e ver o mundo (MARTín JUEZ, 2002). Valorizando-os se contribui para o estabelecimento da harmonia entre o local o e o global, impedindo uma unificação em um mundo cada vez mais globalizado. Danielle Perra (2010) aponta, referindo-se ao Low Cost Design, projeto focado no registro fotográfico da criatividade espontânea da Itália, que com ele contribui-se para a difusão das tradições, dos recursos locais e memórias de uso, 
que fazem parte de uma herança incomensurável, mas também frágil pela produção estandardizada do mercado.

Existem vários exemplos de que o design contribui para impedir a unificação cultural através da apropriação da materialidade da rua e de sua incorporação nos seus trabalhos. É o caso no design gráfico das tipografias inspiradas em paisagens urbanas, e no caso do design de produto, de alguns dos trabalhos dos Irmãos Campana. Assim, o design se conecta com a rua, com a cultura material e imaterial de um lugar e com diversas leituras do dia-a-dia, e evidencia a criatividade e recursividade de pessoas comuns que pertencem a um território. Priscila Farias (2011) no artigo "Aprendendo com as ruas: a tipografia e o vernacular", traz exemplos focados na apropriação por parte do design gráfico das formas vernaculares, e assinala que esse tipo de atitude pode contribuir para a configuração de identidades por meio da expressão visual de elementos locais, que é um dos aspectos mais importantes do papel social do design gráfico (FARIAS, 2011).

Por outro lado, Paul Polak, o CEO da Windhorse International, observa que a maioria dos designers em nível mundial foca os seus esforços no desenvolvimento de produtos e serviços exclusivamente para os $10 \%$ mais ricos dos consumidores mundiais. (POLAK, 2013, apud UNESCO, 2013) Onde está o design focado nos outros 90\%? Pudemos ver que o DND das ruas de Belo Horizonte em sua maioria é praticado por pessoas de baixa renda. Referindo-se a isto, Maria Cecília Loschiavo (2013) assinala que: "É significativo compreender o aspecto estético da criatividade dos despossuídos, porque há um pensamento estereotipado que insiste em revelar apenas o lado sombrio, feio e marginal dessas populações." (SANTOS, 2013, p. 83). Portanto, através do seu estudo pode-se conhecer um outro lado das comunidades de baixa renda associado à criatividade, tentando não impor métodos, nem processos, mas observando e aprendendo o que elas têm para nos ensinar, não só do ponto de vista do design, mas de outros pontos de vista. E provavelmente, também, pode-se romper com estereótipos relacionados à beleza, à qualidade, etc.

É hora de o design dar lugar a outros fenômenos, é hora de colocar os olhos nas ruas, pois como aponta Maria Cecilia Loschiavo, como designers temos muito que aprender sobre esses tipos de manifestações, já que são um "laboratório vivente de criatividade" (SANTOS, 2000, tradução nossa) ${ }^{2}$. Estudando-as podemos adquirir um grande repertório de possibilidades no que diz respeito ao reuso de materiais e às transformações de objetos produzidos em série, podemos aprender como expressam identidade, como o design se relaciona com as ruas, e teremos a oportunidade de repensar a cultura do desperdício da nossa sociedade. (SANTOS, 2000)

Desta forma, podemos dizer que o estudo e o registro das manifestações do DND contribuem para a ampliação da perspectiva do design e das suas áreas de estudo e para o conhecimento da cidade, seus habitantes, suas formas de atuar e criar. Também estimula a apreciação da diversidade cultural, pois os múltiplos usos (ou pósusos) que podem ser dados aos bens de consumo em cada país ou território e as

\footnotetext{
${ }^{2}$ Living laboratory of creativity.
} 
diversas maneiras de materializar a solução de um problema estabelecem diferenças e marcam identidades, que ao mesmo tempo o design pode afirmar através do desenvolvimento dos seus projetos. $O$ estudo também permite ao design focar seus esforços em comunidades de baixa renda, que são comumente esquecidas, e adquirir possibilidades quanto ao reuso de materiais.

\section{REFERÊNCIAS}

BOUFLEUR, Rodrigo. A questão da gambiarra: Formas Alternativas de Desenvolver Artefatos e sua relação com o Design, 2006, 153 p. São Paulo, Dissertação, Programa de Pós-graduação da Faculdade de Arquitetura e Urbanismo, Universidade de São Paulo, São Paulo, Brasil.

BORGES, Adélia (2011). Design pelos outros 90\%. Disponível em: http://www.terceirametade.com.br/\#/2011/03/design-pelos-outros-90/ Acesso em: 12 Nov. 2012

BRANDES, U.; STICH, S.; WENDER, M.; Design by Use. Basel: Birkhäuser. 2009.

BRANDES, Uta., \& Michael, Erlhoff. Non Intencional Design. New York: Daad gmhb. 2006

CARDOSO, Fernanda. Design gráfico Vernacular - A arte dos letristas. 2003. Dissertação (Programa de Pós-graduação em Design) Pontifícia Universidade Católica de Rio de Janeiro - PUC- Rio, Rio de Janeiro, Brasil.

DONES, Vera Lucia. As apropriações do vernacular pela comunicação gráfica. Anais P\&D Design 2004, AEND-BR. 2004

FARIAS, Priscila. Aprendendo com as ruas: a tipografia e o vernacular. In: Marcos da Costa Braga. (Org. ). O papel social do design gráfico: história, conceitos \& atuação profissional. São Paulo: Senac São Paulo, v. , p. 163-183. 2011.

FINÍZOLA, Fátima. Tipografia Vernacular Urbana. São Paulo: Blucher. 2010.

FUKUSHIMA, Naotake. Dimensão social do design sustentável: contribuições do design vernacular da população de baixa renda. 2009. Dissertação (Mestrado em Design), Universidade Federal de Paraná, Programa de Pós-graduação em Design, Curitiba, Brasil. 2009

FULTON SURI, Jane \& Ideo: Thoughtless Acts. Observations on Intuitive Design. San Francisco. 2005.

GUSMÃO, Gabriela. Rua dos Inventos: Desenho Industrial e Responsabilidade social. Perspectivas do ensino de design da pós-graduação, 2001. 
HOUAISS, A. Dicionario Houaiss da Lingua Portuguesa. Rio de Janeiro. Ed. Objetiva. 2001

JENCKS, Charles; Silver, Nathan. Adhocismo. The case of improvisation, New York. 1993.

LAMAS, Antônio; MARQUEZ, Renata Moreira.; CANÇADO, Wellington. MUSEU DE ARTES E OFICIOS (BELO HORIZONTE, MG). Atlas ambulante= Walking atlas. Belo Horizonte, Brasil: Instituto Cidades Criativas, 2011

MAGALHÃES, A. O que o design industrial pode fazer pelo país? In: Revista Arcos, Rio de Janeiro. V.1, 1998, p 8-12. 1977

MARTÍN JUEZ, Fernando. Contribuciones para una antropología del diseño. Barcelona : Gedisa. 2002.

MARTINS, Bruno. Tipografia popular: Potencias do llegível na Experiência do Cotidiano. 2005, 105f. Dissertação (Programa de Pós-graduação em Comunicação Social), Universidade Federal de Minas Gerais, Faculdade de Filosofia e Ciências Humanas. Belo Horizonte.

MARTINS, Fernanda. Letras que flutuam; o abridor de letra e a tipografia vitoriana. Monografia (Pós-graduação lato sensu - Especialização em Semiótica e Cultura Visual) - Universidade Federal do Pará, UFPA, Belém. 2008.

PACEY, Philip. Anyone desinning Anything? Non-professional Designers and the history of Design. In: Jornal of Design History, v.5, n. 3, London. 1992.

PELLEGRINI FILHO, Américo. Comunicação popular escrita. São Paulo: Edusp, 2009.

PERRA, Daniele Pario. Low cost design. Milano: Silvana Editoriale, c2010.

SANTOS, M. Spontaneus Design, Informal Recycling and Everyday Life in Postindustrial Metropolis. Anais do Congresso Politécnico de Milão. Milão . 2000.

SANTOS, Maria Cecilia Loschiavo. Reflexões sobre design e humanism no mundo contemporâneo. In: CELASCHI, F., DE MORAES, D., Cadernos Avançados em Design: Humanismo; Universidade do Estado de Minas Gerais - Barbacena; EdUEMG, 2013.

UNESCO, Development and Dissemination of Innovative Design Solutions to address Extreme Poverty. Disponível em: http://www.unesco.org/new/en/mediaservices/single-

view/news/development_and_dissemination_of_innovative_design_solutions_to_add ress_extreme_poverty/. Acesso em: 2 Jul. 2013. 